\title{
Exploração sexual comercial de crianças e adolescentes: a vivência subjetiva do corpo
}

\author{
Commercial sexual exploitation of children and adolescents: the subjective experience of \\ the body
}

La exploración sexual comercial de niñas y adolescentes: la vivencia subjetiva del cuerpo

\author{
Ana Cristina Serafim da Silva* \\ Maria de Fátima Pereira Alberto*
}

\begin{abstract}
Resumo
Este artigo tem como objetivo analisar as vivências subjetivas relacionadas ao uso do corpo por crianças e adolescentes do sexo feminino, vitimadas pela exploração sexual comercial em João Pessoa-PB. Participaram da pesquisa 14 meninas, entre 14 e 18 anos, que faziam ponto na orla marítima e no centro da cidade, submetidas a entrevista semiestruturada e técnica de análise de conteúdo temático. Os resultados mostraram que a construção da subjetividade dessas meninas por meio do corpo é mediada pela necessidade de sobrevivência, uma infância e adolescência não vivida, ou permeada de violência, de direitos negados, com destaque para a relação desigual do gênero, que se submetem aos poderes dos homens. Tal situação faz com que neguem o corpo, sintam nojo de si e do corpo, por estarem fazendo algo que lhes tira a dignidade e o direito de ser sujeito de direitos.
\end{abstract}

Palavras-chave: Exploração sexual comercial. Vivência subjetiva. Meninas. Corpo.

\begin{abstract}
This article aims to analyze the subjective experiences related to the use of the body of children and adolescent girls, victimized by commercial sexual exploitation in João Pessoa. Interviews were carried out with 14 girls aged 14 to 18 in situations of commercial sexual exploitation in certain parts of the city. Underwent semi-structured interview addressing the experiences of the body, from the moment they discover their body as an object of use by the time of interview technique and subjected to thematic content analysis. The results showed that the construction of subjectivity of these
\end{abstract}

\footnotetext{
Texto recebido em janeiro 2013 e aprovado para publicação em março de 2014.

Doutora em Psicologia Social pela Universidade Federal da Paraíba (UFPB), professora da Universidade Federal do Tocantins, líder do Grupo de Pesquisa e Estudo sobre Infância e Adolescência. Endereço: Rua Oseias Soares Paes, 481 - Setor Canãa, Miracema do Tocantins-TO, Brasil. CEP: 77650-000. E-mail: anacris_serafim@yahoo.com.br.

* Doutora em Sociologia pela Universidade Federal de Pernambuco, professora do Departamento de Psicologia e do Programa de Pós-Graduação em Psicologia Social da UFPB. Endereço: Rua Sebastiāo Interaminense, 369, ap. 202, Ed. Porto Lugano - Bessa, João Pessoa-PB, Brasil. E-mail: jfalberto@uol.com.br.
} 
girls through the body is mediated by several factors, and the need for survival as this factor in all categories, marked by experiences of childhood and adolescence not realized, or permeated with violence, rights denied, to having their first sexual intercourse at the age of 9. Highlighting the unequal relationship of gender, undergoing the powers of men, this power normalized and naturalized by the company kept, who sets out who may or may not belong. This situation causes deny the body, feeling of disgust with themselves and their body, for doing something that takes away their dignity and robs them of the right to be the subject of law.

Keyword: Commercial sexual exploitation. Subjective experience. Girls. Body.

\section{Resumen}

Este artículo tiene como objetivo analizar las experiencias subjetivas relacionadas con el uso del cuerpo de las niñas y adolescentes de sexo femenino, víctimas de la explotación sexual comercial en João Pessoa. Participaron 14 niñas con edades entre 14 y 18 años, que se prostituían en el paseo marítimo y en el centro de la ciudad, sometidas a entrevista semiestructurada y a la técnica de análisis de contenido temático. Los resultados mostraron que la construcción de la subjetividad de estas chicas a través del cuerpo está mediada por la necesidad de supervivencia, una infancia y adolescencia no vivida, o impregnada de violencia, de derechos negados, destacando la relación desigual de género, que les hace someterse al poder de los hombres. Esta situación hace que nieguen el cuerpo, sientan asco de sí mismas y del cuerpo, por estar haciendo algo que les quita su dignidad y el derecho de ser sujeto de derechos.

Palabras clave: Exploración sexual comercial. La experiencia subjetiva. Niñas. Cuerpo.

\section{Introdução}

exploração sexual comercial de crianças e adolescentes (ESCCA) é um
fenômeno que vem ganhando maiores proporçóes no mundo inteiro, e
particularmente aqui no Brasil. Embora presente desde a Antiguidade,
atualmente ganhou maior visibilidade, no que se refere às denúncias, às políticas
e ao enfrentamento.

No entanto, os dados sobre a exploração sexual comercial no Brasil ainda são incertos, o número de casos reais de violência sexual não condiz, em sua totalidade, com o número de denúncias; estes podem ser mais elevados (Alberto, Silva, Gomes, Araújo \& Oliveira, 2009; Habigzang \& Caminha, 2004). Observa- 
se que a concretização da denúncia em si ainda é um aspecto complexo devido às nuances da violência sexual. Segundo o relatório feito pela Polícia Rodoviária Federal (PRF, 2010), a Região Nordeste é a que apresenta o maior número de pontos de ESC, foram detectados 545 pontos ao longo das rodovias; seguido das regiōes Sul, Sudeste, Centro-Oeste e Norte, respectivamente. Com relação ao número de crianças e adolescentes violentados sexualmente, conforme dados do Disque 100 (Brasil, 2013), em 2012, foram registradas 37.726 denúncias de violência sexual contra crianças e adolescentes em todo o Brasil. Em 2013, esse número caiu para 31.895 , uma redução de $15,46 \%$. O que não quer dizer que houve uma diminuição no número de crianças e adolescentes vitimados pela violência sexual, mas houve uma redução nas denúncias feitas, principalmente pelo Distrito Federal e alguns Estados do Nordeste. Especificamente sobre a exploração sexual comercial de crianças e adolescentes, a ESCCA, das 13.247 denúncias feitas de janeiro a março de 2011,34\% referem-se à exploração sexual comercial. A Região Nordeste é a que tem o maior número de denúncias e dos registros de dados sobre violência sexual.

A Exploração Sexual Comercial (ESC) adquiriu diferentes facetas no decorrer de toda história. No Brasil, ela se tornou um elemento cultural sempre presente. No entanto, a partir de 1990, o cenário sobre o fenômeno da exploração sexual comercial de crianças e adolescentes começou a mudar, principalmente em relação à compreensão e enfrentamento. Isso se deu devido à conscientização da sociedade quanto à extensão e complexidade do fenômeno. Com a criação do Estatuto da Criança e Adolescente (ECA) (Lei Federal 8.069/1990), à imagem da nossa Constituição, tornou-se o principal instrumento legal que trata dos direitos das crianças e adolescentes no Brasil, reconhecendo-os como sujeitos de direitos, estabelecendo todo um sistema de garantia destes e de sua proteção integral e integrada. A realização das CPI de 1993 e 1998 (na Paraíba), da CPMI (2004) e dos Congressos Mundiais contra a exploração sexual comercial de crianças e adolescentes (Estocolmo, em 1996; Yokohama, em 2001; Brasil, em 2008) também ajudaram na elucidação conceitual. A prostituição infantil, como era chamada, passou a ser exploração sexual comercial de crianças e adolescentes, pois se entendeu que esses sujeitos não optariam por se prostituírem, e o termo denotava uma parcela de adultos que "optou" pelo comércio do sexo como uma profissão (Faleiros, 2000; Faleiros, 2004; Morais, Cerqueira-Santos, Moura, Vaz \& Loller, 2007).

Nesse sentido, a exploração sexual comercial de crianças e adolescentes pode ser definida como uma relação de mercantilização que envolve o corpo de crianças e adolescentes, seja do sexo feminino ou masculino, para a obtenção de vantagem (ou proveito sexual por um adulto), baseada numa relação de 
poder e de exploração comercial (Leal, 1999; Libório, 2005). Embora exista uma diversidade de conceitos sobre a exploração sexual comercial de crianças e adolescentes, há um consenso sobre o envolvimento de crianças e adolescentes em práticas sexuais em troca de dinheiro, comida, abrigo e, dessa forma, são forçadas a usar o corpo para poder sobreviver (Lau, 2008; Williams, Binagwaho \& Betancourt, 2012).

Essa violência agrava-se devido à estrutura da sociedade, produtora de várias formas de exclusão social, como as desigualdades sociais, culturais, de gênero e raça/etnia, que trazem como consequência alteraçóes na qualidade de vida material (condições de sobrevivência) e nos relacionamentos interpessoais, que se dão tanto em âmbito intra como extrafamiliar (Libório \& Sousa, 2004; Libório, 2005). São esses fatores que, de forma articulada, compõem um cenário para a violência sexual nas suas expressões do abuso e da exploração sexual que, assim, violam os direitos mais elementares das crianças e adolescentes nela envolvidos, comprometendo o desenvolvimento biopsicossocial e a construção da subjetividade desses sujeitos.

A construção da subjetividade desses sujeitos que estão em situação de exploração sexual comercial é abordada neste artigo por meio de quatro categorias: infância e adolescência, subjetividade, corpo, gênero. Essas categorias fornecem aspectos que possibilitam o entendimento de como essas meninas utilizam o corpo na ESC como objeto de exploração, considerando que as sociedades modernas podem ser definidas como sociedades disciplinares, e a disciplina do corpo se constitui a base do controle e vigilância que essa sociedade impóe aos indivíduos (Foucault, 1975/2010). Nesse contexto, procura-se entender como o corpo dessas meninas se adéqua às demandas da sociedade e se torna um corpo disciplinado, enfatizando a dimensão de poder do masculino sobre o feminino, posto que, em sua maioria, são meninas-mulheres que estão em situação de exploração sexual comercial, e como se dá a construção da infância e da adolescência na nossa sociedade, com base nessas vivências.

O estudo se limita ao sexo feminino, dada a dimensão de gênero que se faz presente nas produçôes teóricas (Saffioti, 2000; Leal \& Leal, 2002) que apontam uma maior incidência de meninas na exploração sexual comercial de crianças e adolescentes e considerando-se a relação desse aspecto com o imaginário social, principalmente no Brasil, que faz do corpo feminino objeto de desejo e de exploração (Safiotti, 2000; Libório, 2005), particularmente da menina (Safiotti, 2000; Faleiros, 2000).

Ao se pensar em infância e adolescência na sociedade brasileira, é necessário levar em consideração o contexto no qual estão inseridos. Segundo Teixeira 
(2003), a concepção moderna de infância, fundada no pressuposto de que são pessoas em desenvolvimento, portanto, sujeitos de proteção especial e de direitos, alcançou um grau de universalidade bastante hegemônico nos países com sociedades industriais modernas. Apesar de ter sido adotada como paradigma em âmbito internacional, essa concepção não vem se efetivando no que se refere às condições de vida material das populações de baixa renda. $\mathrm{O}$ ser criança na nossa sociedade se transformou em direito adquirido, e não para todas as classes sociais. E é nesse cenário de ambivalência que a exploração sexual comercial de crianças e adolescentes se inscrevem.

Como chama a atenção Teixeira (2003), a Psicologia do desenvolvimento não tem sido capaz de, ao abordar o desenvolvimento do homem e de suas condiçôes de vida, considerar as condiçôes econômicas, sociais e culturais nas quais se inserem os homens. Contribui, assim, significativamente, para ocultar essas condições, que têm peso considerável quando de sua constituição como "ser". É nesse sentido que a Psicologia sócio-histórica traz consigo a possibilidade de crítica, sendo o homem concebido como síntese de múltiplas determinações, cuja subjetividade é construída material e historicamente, sempre como resultado de gerações anteriores (Vygotsky, 2007). O desenvolvimento não é pensado de forma linear, mas como um todo que se processa numa dimensão social, o que permite compreender o desenvolvimento humano articulado às relaçôes sociais, fornecendo elementos que permitam compreender que sujeito é esse que se constrói baseado no meio e na cultura (Alberto \& Santos, 2011).

As condições objetivas da vida material, tais como a vivência em família, as violências pelas quais se submetem as meninas, a naturalização da violência sexual contra crianças e adolescentes (logo, contra si mesmas) (Safiotti, 2000), a posição de passividade, dependência e vulnerabilidade às quais estão submetidas algumas crianças e adolescentes em situação de violação sexual (CerqueiraSantos, Rezende \& Correa, 2010), o meio social em que estão inseridas são fatores que influenciam na construção da infância e da adolescência (Ozella, 2002; Teixeira, 2003; Calil, 2003).

Dessa forma, compreendemos a construção da subjetividade do sujeito como um processo contínuo, que se dá num determinado contexto, fruto de sua pertença a grupos sociais, em que se concretiza em suas relações de produção de subjetividade e de sua realidade. Segundo Delari Júnior (2009, como citado em Alberto \& Santos, 2011), o desenvolvimento psicológico é marcado por conflitos e pela alternância entre períodos estáveis e críticos que ocorrem em determinadas condições materiais de vida. 
Embora a exploração sexual comercial de crianças e adolescentes resulte de uma multiplicidade de fatores, ela é vista como trabalho precoce, uma vez que se refere ao processo de tirar proveito do trabalho sexual de outros, forjando um mercado do sexo. Segundo Alberto (2002), a inserção de crianças e adolescentes das classes populares no trabalho é pensada como uma forma de disciplinamento por ser concebida como uma alternativa para as crianças pobres, como uma forma de prevenir a marginalidade e adestrá-las para o mundo do trabalho.

E é nesse sentido uma das principais ideias de Foucault (1975/2010), a de que as sociedades modernas são definidas como sociedades disciplinares. A disciplina do corpo se constitui a base do controle e vigilância que a sociedade impôs aos indivíduos. Visto que o corpo está mergulhado num campo político, as relaçôes de poder têm alcance imediato sobre ele; elas o investem, marcam-no, dirigemno, supliciam-no, sujeitam-no a trabalhos, exigem-lhe sinais. Esse investimento político do corpo está ligado, segundo relações complexas e recíprocas, à sua utilização econômica; é numa boa proporção, como força de produção, que o corpo é investido por relações de poder e de dominação, mas, em compensação, sua constituição como força de trabalho somente é possível se ele está preso num sistema de sujeição (onde a necessidade é também um instrumento político cuidadosamente organizado, calculado e utilizado) (Foucault, 1975/2010).

O corpo da menina explorada sexualmente é marcado, sujeito ao trabalho, os mais variados possíveis, investido de relações de poder e dominação, preso a um sistema cuja necessidade de sobrevivência, que é esse instrumento político organizado, é quem funciona como força motriz para essa sujeição. Como sujeitos que já são excluídos da sociedade, são treinados para poder suportar essa violência, criando mecanismos que justificam ou, pelo menos, explicam sua condição, enquanto submetidas à ESC.

De acordo com Alberto e Santos (2011), no desenvolvimento, a constituição dos sujeitos se dá pela construção compartilhada de significados e pela internalização de modos de fazer. Esses dois aspectos fazem com que a criança comece a interiorizar esse imaginário presente na sociedade brasileira, da naturalização da exploração sexual comercial, do fim da infância e da necessidade de sobrevivência. Essa atividade determina a consciência desses sujeitos e suas relaçôes com o meio, fazendo com que carreguem consigo o estigma de sujeitos excluídos da sociedade, marcados pela violência e sujeição às diversas práticas que violam constantemente seus direitos.

É desse modo que se pensa aqui a construção da subjetividade dessas meninas que, pelo entrelaçamento dos diversos micropoderes, elabora e se empodera de discursos que têm como finalidade controlar seus atos, principalmente os que 
vão de encontro às normas impostas por essa sociedade. É dessa forma que, de acordo com Foucault (1975/2010), constituem-se os sujeitos, vendo o lugar onde está inserido, para saber quais micropoderes ali atuam e influenciam na constituição dessa subjetividade, com base em qual verdade o sujeito se apropria para tomar como sua.

Este artigo analisa as vivências subjetivas relacionadas ao uso do corpo por crianças e adolescentes do sexo feminino vitimizadas pela exploração sexual comercial e o processo de construção subjetiva dessas meninas pelo uso desse corpo.

\section{Método}

\section{Participantes}

Participaram desta pesquisa 14 adolescentes do sexo feminino vitimizadas pela ESCCA. A pesquisa foi realizada em locais identificados por pesquisas anteriores como sendo pontos de exploração sexual comercial. Para seleção da amostra, utilizou-se o critério de saturação (Sá, 1998), no qual o número de sujeitos é definido a posteriori, quando da coleta, a partir da repetição das informações dos relatos das entrevistadas, possibilitando a contemplação dos objetivos traçados na pesquisa.

\section{Instrumentos}

Quanto ao instrumento, utilizou-se de entrevista semiestruturada, composta por duas partes. A primeira versava sobre dados biossociodemográficos, e a segunda parte direcionada por temas norteadores a partir do momento em que a menina descobre o corpo como forma de sobrevivência e o uso desse corpo até o momento da entrevista.

\section{Procedimentos}

Para a coleta de dados, foram realizados alguns procedimentos: territorialização, observação e obtenção das entrevistas semiestruturadas. Primeiramente foi feito a territorialização, que permitiu o acesso às participantes. Esta é uma técnica específica de observação e aproximação ao espaço da rua - local de domínio dos sujeitos, para ser possível o contato (Graciani, 1997). Juntamente com a territorialização, passamos à observação dos pontos em que ficavam as meninas, da constância delas nesses pontos, da movimentação de clientes e também de meninas, do número delas em cada dia da semana, da organização da atividade de trabalho, do comportamento dos transeuntes para com elas, e da relação 
que elas tinham entre si. Pela observação, foi possível efetuar os convites para participar da pesquisa e realizar as entrevistas.

Quanto aos locais identificados como tendo pontos de exploração sexual comercial, um localizava-se na Orla Marítima e outro no Centro da cidade. Os procedimentos acima citados foram realizados nos dois locais. Todas as entrevistas foram feitas pela primeira pesquisadora, que contava com o auxílio de uma colaboradora para as entrevistas realizadas na Orla Marítima, e a colaboração de educadores sociais, para as entrevistas realizadas no Centro. Durante o período de coletas de dados, a pesquisadora comparecia, uma vez por semana, aos locais identificados como pontos de exploração sexual.

\section{Procedimentos éticos}

Os aspectos éticos que garantem a integridade dos participantes deste estudo foram assegurados com base na Resolução no 196 do Conselho Nacional de Saúde, que consiste em diretrizes e normas para regular as pesquisas com os seres humanos (Resolução $n^{\circ}$ 196/1996). Em se tratando de estudo realizado com população especial (menores de 18 anos), os termos de consentimento livre esclarecido foram assinados pela coordenadora do Programa Sentinela, programa do governo federal que atendia crianças e adolescentes vítimas de violência, principalmente a violência sexual, e que buscava garantir os direitos mais fundamentais desses sujeitos.

\section{Resultados e discussão}

Para o tratamento dos dados, utilizou-se da técnica de análise de conteúdo temático de Bardin (1977), enfatizando-se a ausência ou a presença do tema, a despeito de sua frequência. Procedeu-se à transcrição integral das entrevistas, em seguida, fez-se a leitura flutuante, a fim de conhecer o conteúdo e, então, captar as primeiras impressões e orientações a partir de sua análise. Os dados foram tabulados para se fazer o recorte das unidades temáticas; codificados, com a finalidade de agrupar o recorte das unidades temáticas e construir as categorias; e categorizados, com o objetivo de elaborar uma representação simplificada do conteúdo. Por fim, realizou-se inferência e interpretação dos dados, com o intuito de descrevê-los e estabelecer relações com os fundamentos teóricos adotados.

O processo de categorização se deu pelo procedimento por "caixas". De acordo com Bardin (1977), parte-se de categorias teóricas, previamente construídas, decorrentes dos funcionamentos teóricos, que foram construídas com base no roteiro de entrevista e, de certa forma, guiavam e continham o objetivo do trabalho. São elas infância e adolescência, gênero, corpo e subjetividade. 


\section{Perfil biossociodemográfico}

As meninas entrevistadas tinham idades variando entre 14 e 18 anos. Com relação à etnia, a grande maioria se denominou como morena e negra, dado encontrado também por vários autores em pesquisas desenvolvidas, em que há uma maior prevalência de meninas de etnia negra, considerando-se também morena e parda, vitimizadas sexualmente no Brasil (Leal \& Leal, 2002; Libório \& Souza, 2004; Libório, 2005; Alberto, 2002; Faleiros, 2000).

Com relação ao estado marital das meninas, 11 disseram estarem solteiras na época da pesquisa; destas, 4 já tinham se casado e se separado; e outras 3 estavam casadas no momento da pesquisa. Das 14 meninas entrevistadas, 6 delas tinham filhos, e uma estava grávida no momento da pesquisa. A maioria disse que moravam com a família, entre os membros citados, pais, avós e filhos; outras tinham saído de casa e foram morar nas ruas, devido à violência familiar e até mesmo abandono dos pais. No que diz respeito à escolaridade, 6 delas disseram não estudar; as outras cursavam séries do ensino fundamental.

\section{Infância e adolescência}

Essa categoria trata do sentimento de infância e adolescência vivenciado e construído pelas meninas em situação de ESC, a partir das várias violências a que estavam submetidas, considerando o meio social como fator principal de construção de subjetividade. Diante disso, a análise dos relatos das meninas entrevistadas permitiu o surgimento de algumas subcategorias: primeira relação sexual quando criança, infância na rua, abandonada pelos pais, conflito familiar/ drogas.

De acordo com as entrevistas, grande parte dessas meninas teve sua primeira relação sexual quando criança, aos 9, 10 e 12 anos de idade, o que revela a complexidade do problema e a concepção que esta sociedade tem para com suas crianças. Pesquisas confirmam que há formas diferenciadas de infância e adolescência, variando de acordo com o nível social (Ozella, 2002; Teixeira, 2003; Calil, 2003). Relato de duas entrevistadas ao ser perguntado sobre a primeira relação sexual:

(risos) Minha primeira relação sexual ... (pausa) foi com um menino, mas já faz tempo [...] deixa eu ver (pausa), faz 8 anos já [...]. Eu tinha 9 [...] na casa dele! Ele me chamou pra ir pra casa dele, aí eu fui mais ele. E era mais velho do que eu 2, 2 ano [...], a mãe dele tava lá e tudo! (17 anos).

Rapai, foi ruim pra mim, né?! Eu não gostei muito não... (risos) por nada, porque eu senti um negócio meio 'rim', dor... Foi com o pai dos meus 2 filhos, com 10 anos de idade... (16 anos). 
O que se identifica é que não há para esses segmentos uma demarcação simbólica entre infância e adolescência, pois algumas dessas meninas começaram sua vida sexual precocemente, aos 9, 10 anos de idade, conforme relatos, quando ainda eram consideradas crianças, de acordo com o ECA. Essa violência se faz presente tão cedo na vida dessas meninas que ela não é percebida como tal, e tão logo é naturalizada. Ao se conceber que uma criança de 9 anos teve sua primeira relação sexual, quando o seu corpo não estava no seu desenvolvimento pleno, sua anatomia sexual ainda estava em evolução, o que poderia trazer o desconforto da dor durante a primeira relação sexual, pode-se pensar que a vivência dessas crianças foi permeada de violência sexual, social, estrutural, familiar e pela negligência. Nesse sentido, os dados revelam que há quem viva a infância e adolescência e há quem não as vive.

Ainda de acordo com os dados coletados nesta pesquisa, algumas das meninas entrevistadas estavam nas ruas desde pequenas, foram abandonadas pelos pais ou a mãe não tinha como sustenta-las, e cedo foram para as ruas procurar um meio de sobreviver. E a entrada na ESC se deu devido à necessidade de sobrevivência, e a própria condição de rua as deixou expostas a vários fatores que vulnerabilizavam a entrada na ESC.

Com relação ao conflito com a família/uso de drogas, os dados dessa pesquisa revelaram que o estar em situação de rua deixava mais vulnerável o acesso e o uso de substâncias psicoativas, sendo comum o uso de drogas pela maioria das crianças e adolescentes que se encontravam em situação de rua, seja para enfrentar todos os problemas ou para poder esquecer um pouco sua condição de abandonada. $\mathrm{O}$ que gerava a dependência e fazia com que essas meninas utilizassem o corpo como meio de poder ter dinheiro e comprar a droga. Sobre o uso de substâncias psicoativas fala uma entrevistada: "Se num fosse pra... Se eu num precisasse, eu num fazia programa e num usava droga. Assim, porque a droga eu se envolvi porque tava muito conflito com minha família, muito assim nos nervos, e não sabia o que fazer" (15 anos).

A violência que permeia o seio familiar é um fator de risco para a ida de muitas crianças e adolescentes para a rua, como meio de superar essas violências, já que esta fragiliza intensamente os laços afetivos (Alberto, 2002; Alberto et al., 2009). Uma vez nas ruas, essas crianças e adolescentes ficavam sujeitas a todo tipo de violência, e vulneráveis ao uso de drogas. Diz uma entrevistada sobre o uso do corpo para comprar drogas:

[vendia nosso corpo] ou algumas [meninas] 'pa' usar drogas, algumas meninas 'pa' usar droga. Uma vez dessa, quando eu comecei a viciar em crack, eu peguei, comecei a fazer programa 'pa' comprar, pagar e vender meu corpo 'pa' poder comprar 'noia', pedra assim, 'pa' eu puder fumar... (15 anos). 
De acordo com Bucher (1996, como citado em Calil, 2003), a droga acaba sendo uma estratégia de sobrevivência para os meninos e meninas em situação de rua, já que seus efeitos ajudam a combater sensações de angústia, abandono, perseguição e fome, permitindo, que por poucos momentos, esses sujeitos esqueçam sua situação de abandonado e as opressões sofridas no espaço ameaçador das ruas.

\section{Corpo}

Esta categoria diz respeito à imagem corpórea que as meninas tinham de si, que elas usavam e também era atravessada por micropoderes que visavam à mercantilização e à disciplinarização do corpo. Percebeu-se que, ao expressarem a percepção com relação ao corpo, havia nas falas das meninas elementos representativos da forma como a sociedade vê, percebe e trata o corpo. A análise do conteúdo das suas falas sobre o corpo revelou a presença de subcategorias: forma mercantilizada de ganhar dinheiro, valorização do corpo, imagem mais velha/acabada devido à ESC.

O corpo era visto como meio de sobreviver, de "trabalhar", de sustentar os filhos e se manter, era uma forma de ganhar dinheiro, um trabalho, de acordo com as falas da maioria das meninas pesquisadas: "Forma de [...] não, forma de [...] a minha forma de ganhar dinheiro, né. O meu corpo é [...]" (16 anos). Isso encontra respaldo em autores que consideram a ESC como um trabalho e que a formação econômica social e cultural da América Latina serviu de panorama para o surgimento da ESCCA, que, juntamente com a precariedade do mercado de trabalho, principalmente para as mulheres, levou à transformação dos seus corpos em mercadoria sexual voltada para o consumo (Faleiros, 2000; Faleiros, 2004; Libório, 2003; Libório \& Souza, 2004; Alberto, 2002; Leal \& Leal, 2002).

Havia um destaque para a valorização do corpo, que despertava desejos; outras o viam com uma aparência mais jovem do que a idade aparentava. A imagem corporal passou a representar a forma de identificação do sujeito, em que juventude, beleza, sedução saúde e vitalidade, e como nos diz Pereira (2004), são atributos veiculados nos discursos que perpassam nos jovens, carregando no seu corpo, além de sua imagem, seu poder. A frase a seguir mostra essa valorização do corpo pelas meninas: "Acho [meu corpo] bonito! ... Não totalmente só meu corpo, meu rosto, também sou bonita, sou linda! (risos)" (17 anos).

Por outro lado, algumas meninas tinham uma imagem negativa do corpo, mais velha/acabada devido à exploração sexual comercial. Elas disseram sentirem nojo, não conseguirem olhar para o corpo e somente o viam como objeto de uso. Autores como Alberto (2002), Leal (1999), Faleiros (2000), Libório (2003), Teixeira (2003) corroboram com esses dados, de que há um sentimento de negação das meninas que estão na ESC, elas têm uma autoimagem negativa 
de si, incluindo o corpo desgastado, usado, esfacelado e maltratado, uma baixa autoestima com sentimentos de inferioridade, sem aspiraçôes e desejos. Fala sobre a percepção do corpo: "Eu num gosto de nada no meu corpo ... Sei lá, eu tenho ódio do meu corpo. Sei lá, você fica com nojo de você 'própia' quando você [...] depois que você faz esses negócio. Não consegue tirar da cabeça não. Você fica com nojo de você!" (15 anos).

O corpo é negado de todas as formas, quando não se pode fazer o que deseja, quando o direito de viver uma sexualidade segura e respeitada é negado, quando o corpo é visto de forma esfacelada e acabado. $\mathrm{O}$ que acarreta prejuízos diversos ao sujeito, entre eles, a baixa autoestima e estigmatização, inclusive por parte dos mesmos sujeitos que estão na ESC.

Dessa maneira, entende-se o corpo como sendo fonte de poder, por onde perpassa vários micropoderes. É o corpo capturado pelos mecanismos de poder e o corpo transformacional ou criativo, que se adéqua às demandas de uma sociedade, que prega o corpo como objeto de significação da subjetividade de que fala Foucault (1975/2010). O corpo, em vez de ser entendido como lugar onde o homem domina o prazer, tornando-se senhor de si, passa a ser visto como um lugar de fragilidade arrebatado por outras forças, micropoderes que controlam e concebem quais os comportamentos adequados.

\section{Gênero}

Nessa categoria, destaca-se sobremaneira a dominação do masculino sobre o feminino, surgem, das falas das meninas, algumas subcategorias, tais como a mulher que tem de sustentar a família, função do feminino, abuso de poder do homem sobre mulher/menina.

Algumas meninas expressaram que os companheiros com quem tinham uma vida marital as obrigavam a fazer programa e lhes sustentar a família, impedindo inclusive que elas desempenhassem outra atividade de trabalho, de modo que exerciam sobre elas um domínio. Outras tinham sido abandonadas pelo pai de seus filhos e tinham de sustentá-los.

Nas famílias das camadas populares, o trabalho feminino assume muito mais o sentido de um benefício para a família do que uma afirmação da individualidade, como ocorre nas famílias de classes médias (Sarti, 2003). Mesmo assim, as relações familiares ainda seguem um padrão de autoridade e hierarquia, o que dificulta a afirmação individual, tendo o homem ainda como a autoridade maior. O trabalho individual das mulheres não tira o lugar de autoridade do homem. 
De acordo com as entrevistas, surgem funções ditas específicas para mulheres, tais como de servir aos homens nas relações sexuais. A construção da mulher é tida como uma construção material e ideológica do objeto de desejo do outro. A fala a seguir ilustra esse uso/abuso do corpo feminino:

Aí eu num sabia que ele tava bebo. Na hora que eu fui notar, ele tava bebo, quereno puxar, quereno, dizeno que num dá dinheiro a mim, quereno me agarrar à força! Eu peguei, gritei e corri ligeiro. Abri a porta na hora que ele foi pegar, ele foi tirar a roupa dele, eu peguei abri a porta e corri. Ele pegou e queria me agarrar à força, queria fazer porque queria comer eu por [...] de todo jeito. Queria comer todo local meu. Aí eu peguei e disse que num queria. Eu só fazia na frente, somente. Num dava minhas outras parte não. Aí eu peguei na hora puxei, abri a chave bem ligeiro assim nervosa e corri (15 anos).

A fala relata bem essa posição de inferioridade do ser mulher na nossa sociedade, principalmente quando se trata de crianças e adolescentes que usam o corpo, deixam-nas mais vulneráveis ao ataque dos homens "viris" que justificam seus atos, já que são meninas que vendem o corpo. Essa construção de que ao homem cabe a posição de dominação, não somente na relação sexual, mas de uma forma geral, é característica de um contexto histórico específico. Consideramos essas categorias como construídas socialmente por uma determinada sociedade, que perpassam micropoderes que tornam mais eficientes os discursos, que naturalizam e corrigem.

$\mathrm{O}$ abuso de poder do homem sobre a menina se refere à supremacia do homem como detentor da força e virilidade (Saffioti, 2000), que tem de ser mostrada pela relação sexual forçada, e o estar em situação de rua ou na ESC a torna vulnerável às violências e agressões do homem. Nesse sentido, a produção da subjetividade da menina-mulher é engendrada pela divisão sexual do trabalho e pelas relações de sexo.

\section{Subjetividade}

A categoria subjetividade surge com base no material analisado e apresentase como a forma com que essas crianças e adolescentes são afetadas, ante a pauperização, as muitas violências, o uso do corpo na exploração sexual comercial; a forma como constroem e vivenciam esse processo de subjetivação e que mecanismos elas usam para explicar sua entrada e, ou, permanência na ESC. As subcategorias que surgiram foram: como vivenciam, mecanismos para permanecer na ESC, mecanismos para sair da ESC, ESC como estratégia de sobrevivência. 
Quanto à forma como vivenciam, as meninas falam sobre sua experiência na ESC, o que sentem após cada programa. Algumas dizem se sentir normal após o programa, pois é a forma de elas ganharem dinheiro; outras se sentem bem, gostam do que fazem. Porém a maioria das meninas disse que "não gosta" de fazer programa, "não se sentem bem", "não sente prazer", "tem nojo", "tem raiva", "sentem-se mal"; outras sentem "medo", "sentem-se estranhas"; sentem-se "aliviadas" quando termina; algumas disseram que se sentem mal, por estarem fora dos padrōes estabelecidos pela sociedade, as pessoas falam e olham para elas de forma diferente. A fala a seguir ilustra esse sentimento: "Porque eu me sinto assim, que os outros assim [...] Tem algumas pessoa que sente nojo de outras pessoa que faz isso, esse negócio... Progama... É, se soubesse, acho que eu me sentiria assim, né. No lugar deles, eu me sentiria assim" (15 anos).

A prática social vivenciada pelas meninas vítimas da exploração sexual consiste em sentirem-se vulgares devido à atividade que desempenham. Sentemse inferiorizadas nas relações com outras pessoas e incapazes de desenvolver-se no sentido de mudar de vida. A exploração sexual comercial em si é uma atividade que as meninas concebem como degradante e vergonhosa, embora se defendam imediatamente: "mas precisam sobreviver" e é "a única forma de que dispõem".

Para Foucault (1979/2007), o sujeito é constituído e não constituinte, sendo um produto histórico, fruto da necessidade cultural de se chegar à verdade. É também constituído por práticas disciplinares, das quais surge um tipo de saber "organizado em torno de uma norma que possibilita controlar os indivíduos ao longo de sua existência”. Essa norma é a base do poder/saber, que se dará sobre os sujeitos, de várias formas e com enormes efeitos. Nesse sentido, as instituições disciplinares, entre elas a sociedade, têm esse poder de coagir e fazer com que essas meninas tenham nojo do que fazem, já que a atividade é vista por todos como vergonhosa.

O exercício do poder cria saber, e o saber acarreta efeitos de poder. O poder opera por meio de discursos, especialmente os que veiculam e produzem verdades. A verdade é, desse modo, produzida por múltiplas e variadas restrições; ela não está fora do poder nem é possível sem o poder. Os regimes de verdade são essenciais às estruturas e ao funcionamento da sociedade (Foucault, 1979/2007). O mesmo discurso que permeia a sociedade sobre o uso do corpo na ESC é introjetado também pelas mesmas meninas que fazem uso do seu corpo, o que faz com que tenham nojo do próprio corpo, e ainda pega o discurso do outro como seu, ao afirmar que, se estivesse no lugar do outro, e o outro aqui é a sociedade, sentiria nojo de quem fizesse programa. 
Dessa forma, pode-se explicar o fato de as meninas em situação de ESC sentirem nojo de si, do corpo, de se sentirem à margem da sociedade, pela mediação do olhar do outro, das palavras, do tratamento, da estigmatização da sociedade, possibilitando a incorporação e a reprodução de um sujeito que se vê excluído da sociedade.

Assim, Foucault (1979/2007) mostra que é preciso ver o lugar do sujeito, o contexto onde está inserido, e quais micropoderes influenciam na constituição da subjetividade, com base em qual verdade o sujeito se apropria para constituir como sua. Essa subjetivação é mostrada nos corpos. É neles que se inscreve a história, perpassada pelos vários poderes.

$\mathrm{O}$ que as meninas vivenciam e se submetem diariamente, suas experiências com o outro, o que por elas é vivenciado na sua relação com a sociedade é por elas incorporado de tal forma que as faz se sentirem da forma como é vivenciado externamente.

As meninas também usam de alguns mecanismos para permanecer na ESC. São formas que elas usam para poder suportar sua permanência e também enfrentarem a vida na ESC. Entre os mecanismos utilizados, o uso de drogas foi relatado por parte delas como sendo uma forma de aguentarem a vida na exploração sexual comercial, e acabam usando o corpo, posteriormente, para manterem o vício; a influência de outras pessoas também é um dos mecanismos que mantêm as meninas na ESC, como marido e amigas; assim como o lugar onde deixam o dinheiro também funciona como forma de se manterem na ESC e de se protegerem contra a violência ou o não pagamento por parte dos clientes, utilizando-se de mecanismos, como deixar o dinheiro com as amigas no ponto de ESC.

Assim como também existem mecanismos para sair da ESC. Entre eles estão a ajuda de parceiros e instituições, que são apontados como mecanismos que ajudam a deixar as drogas, a sair das ruas e da exploração sexual comercial.

$\mathrm{Na}$ maioria das entrevistas, a ESC como estratégia de sobrevivência foi o aspecto que mais se sobressaiu, sendo usado como justificativa para a inserção das meninas na ESC, que não tinham outra opção, encontrando respaldo nos achados de muitos autores, entre eles Libório \& Souza (2004), Faleiros (2000), Faleiros (2004), Leal \& Leal (2002), Alberto (2002). O que vai de encontro a toda legislação internacional e nacional que preza a garantia dos direitos mais elementares às crianças e adolescentes.

Não se pode deixar de considerar a vivência desses sujeitos inseridos na ESC, que se submetem a essa violência contra o corpo, contra sua integridade física, de forma a procurar entender o modo como vivenciam e constroem sua 
subjetividade, que diante das adversidades culturais, socioeconômicas, históricas, políticas, éticas e moralistas da sociedade, constituem-se como sujeito, perpassado e marcado também por todas essas violências. Mas que, mesmo assim, criam os seus mecanismos de sobrevivência, ou sonhando em sair da ESC, com ou sem a ajuda de outras pessoas e instituições, ou mesmo tendo de se submeter a essa violência, aos ditames da sociedade disciplinar, que estipula espaços para todos, mesmo para aqueles que vivem à margem da sociedade. Esta produz um discurso e se utiliza de micropoderes tão eficientes que controlam os que à margem sobrevivem.

Utilizando-se dos escritos de Foucault $(1975,1979)$ é que se procura entender a constituição do sujeito como sendo fruto da sociedade, que tem por base o controle e a disciplina. Essa disciplina se aplica de forma mais esquemática ao corpo, que fica submetido à vigilância da sociedade ou dos seus micropoderes, que controlam a forma como cada um deve se comportar, criando, desse modo, sujeitos que ficam submetidos aos ditames da sociedade disciplinar.

É dessa forma que se pensam essas meninas exploradas sexualmente, que já foram e se sentem excluídas da sociedade. Os micropoderes agem sobre elas, de forma que estas vão reproduzindo o que lhes é insuflado, para poder suportar essa violência, criando mecanismos que justifiquem ou que possam assegurar sua sobrevivência nesses espaços. Dessa forma, torna-se extremamente difícil a saída dessas meninas da ESC, pois os mecanismos que a sociedade cria atuam de forma tão eficaz, estigmatizando e menosprezando, que elas mesmas como sujeitos assim se sentem.

\section{Considerações finais}

Constatou-se que, para as meninas em situação de ESC que fazem pontos nas ruas, o fator desencadeador do uso do corpo como objeto de exploração foi uma conjunção de fatores: desde o uso de drogas, a influência de outras pessoas, devido à condição de rua, porque quis mesmo e devido à necessidade de sobrevivência. Esta é um fator de peso no encaminhamento de meninas para a ESC, aliado muitas vezes às experiências, na infância e adolescência, de violência, considerando ser um sujeito que ainda está em desenvolvimento e que nem o corpo está na sua completa formação.

Os dados aqui encontrados confirmam estudos de que a infância termina cedo para as classes pobres e que há uma forma diferenciada de se viver a infância e adolescência, dependendo do contexto social em que se está inserido. É essa forma diferenciada de se viver a infância que contribui enormemente para uma vivência subjetiva também diferenciada, visto que é de extrema relevância o 
contexto em que essa criança e, ou, adolescente está inserida, a forma como lhe insuflam e como aprende o ser criança, os constitui como ser, e, nesse caso, como sujeitos sem direitos, desrespeitados.

A divisão sexual do poder é elemento constitutivo das relações sociais baseadas nas diferenças entre os sexos. Essas diferenças contribuem para o exercício de papéis estereotipados, devendo, mais uma vez, adequar-se aos ditames sociais normatizados e naturalizados. Tudo isso faz com que essas meninas não se vejam como sujeitos pertencentes à sociedade, mas sim excluídos, sem direitos, chegando a sentir nojo do corpo, sentindo-se mal por estarem fazendo uma atividade humilhante, degradante, que lhes tira a dignidade, que é mal vista aos olhos da sociedade, tendo que aguentar, muitas vezes, humilhações e violências de clientes e da sociedade.

A vivência subjetiva baseada nessas demandas vai sendo um fator mediador na construção desse sujeito demarcado por uma experiência de infância e adolescência não vivida ou permeada de violência, de direitos negados, com destaque para a relação desigual do gênero, pela qual mulheres, crianças e adolescentes se submetem ao poder dos adultos homens. Em que o corpo passa a ser visto como a forma de ganhar dinheiro e sobreviver, que precisa se adequar às demandas dos outros. Os micropoderes da sociedade agem de tal forma que levam essas meninas a viverem à margem, a desconhecerem seus direitos, a não perceberem que não tiveram uma infância, que lhes foi negado o direito a ter uma vida digna, a negar o próprio corpo e o fazer calar mesmo quando esse corpo se sente abusado, mutilado. Nesse caso, as meninas passam a sentir nojo de si, do seu corpo, a anularem-se, a não terem valor como sujeitos e merecedoras das violências sofridas. Pois foi assim que viveram uma infância e é assim que elas se constituem como sujeitos.

É dessa forma que identificamos a construção da subjetividade dessas meninas, pelo uso do corpo na exploração sexual comercial, que não tem uma única causa, mas que está atrelado a diversas causas, tendo a necessidade de sobrevivência como fator desencadeador que se faz presente em todas as categorias, aliado à violência estrutural, social, sexual, física, psicológica, e que é levado a entrar na ESC, influenciado pelos vários fatores e violências, tendo de adequar o corpo às demandas exigidas pelos clientes/exploradores, que abusam de um corpo que foi violado e a quem foi negado o direito a ter direito. É na articulação dessas várias categorias aqui apresentadas, de exclusão social, de violência, de negação de direitos, do abandono, do ser menina/mulher, numa sociedade que dá amplos poderes aos homens, que expressam pela sexualidade sua virilidade e superioridade, encontrando nessas meninas que, vítimas que são, tornam- 
se presas fáceis, já que estão em situação de vulnerabilidade social que vão se constituindo como sujeitos. Muitas vezes, a ESC é o único meio que encontram de poder sobreviver. 


\section{Referências}

Alberto, M. de F. P. (2002). A dimensão subjetiva do trabalho precoce de meninose meninas em condição de rua em João Pessoa-PB. (Tese de Doutorado). Programa de Pós-Graduação em Sociologia, Universidade Federal de Pernambuco, Recife.

Alberto, M. F. P. \& Santos, D. P. (2011). Trabalho infantil e desenvolvimento: reflexões à luz de Vigotski. Psicologia em estudo, 16(2), 209-218.

Alberto, M. F. P., Silva, A. C. S., Gomes, V. C., Araújo, A. M. G. \& Oliveira, D. (2009). A exploração sexual infanto-juvenil sob a ótica de membros da população. Psicologia em Revista, 15(3), 41-59.

Bardin, L. (1977). Análise de conteúdo. Lisboa: Edições 70.

Brasil (2013). Secretaria de Direitos Humanos da Presidência da República. Disque Denuncia Nacional de Abuso e Exploração Sexual contra Crianças e adolescentes: DDN 100. Recuperado de http://www.disquedenuncia.sedh.gov. br.

Calil, M. I. (2003). De menino de rua a adolescente: análise sócio-histórica de um processo de ressignificação do sujeito. In S. Ozella (Org.), Adolescências construidas: a visão da psicologia sócio-histórica. (pp. 137-166). São Paulo: Cortez.

Cerqueira-Santos, E., Rezende, N. \& Correa, P. (2010). Adolescentes vítimas de exploração sexual: um estudo de casos múltiplos. Contextos Clínicos, 3(2),113123.

Faleiros, E. T. S. (2000). Repensando os conceitos de violência, abuso e exploração sexual de crianças e adolescentes. Brasília: Thesaurus.

Faleiros, V. de P. (2004). O fetiche da mercadoria na exploração sexual. In R. M. C. Libório \& S. M. G. Sousa (Orgs.), A exploração sexual de crianças e adolescentes no Brasil: reflexōes teóricas, relatos de pesquisas e intervençôes psicossociais. (pp. 51-72). São Paulo: Casa do Psicólogo.

Foucault, M. (1975). Vigiar epunir. Petrópolis: Vozes, 2010. (Original publicado em 1975)

Foucault, M. (1979). Microfisica do poder. Rio de Janeiro: Graal, 2007. (Original publicado em 1979) 
Graciani, M. S. S. (1997). Processo de abordagem das crianças e adolescentes "de e na" rua: desafios e perspectivas. Revista Brasileira de Crescimento e Desenvolvimento Humano, 4(1), 55-64. Recuperado a partir de http://www. revistas.usp.br/jhgd/article/view/38126/40858.

Habigzang, L. F. \& Caminha, R. M. (2004). Abuso sexual contra crianças e adolescentes: conceituação e intervenção clínica. São Paulo: Casa do Psicólogo.

Lau, C. (2008). Child prostitution in Thailand. Journal Child Health Care, 12(2), 144-155.

Leal, M. L. P. (1999). A exploração sexual comercial de meninos, meninas e adolescentes na América Latina e Caribe: Relatório Final - Brasil. (2a ed.). Brasília: Cecria, UNICEF.

Leal, M. L. P. \& Leal, M. F. P. (2002). Pesquisa sobre tráfico de mulheres, crianças $e$ adolescentes para fins de exploração sexual no Brasil - PESTRAF: Relatório Nacional-Brasil. Brasília: Cecria.

Lei Federal no 8.069, de 13 de julho de 1990 (Julho, 1990). Dispóe sobre o Estatuto da Criança e do Adolescente e dá outras providências. Brasília: Senado Federal.

Libório, R. M. C. (2003). Desvendando vozessilenciadas: as adolescentes em situação de exploração sexual comercial. Tese (Doutorado). Instituto de Psicologia da Universidade de São Paulo.

Libório, R. M. C. (2005). Adolescentes em situação de prostituição: uma análise sobre a exploração comercial na sociedade contemporânea. Psicologia: Reflexão e Critica, 18(3), 413-420.

Libório, R. M. C. \& Souza, S. M. G. (2004). (Orgs.), A exploração sexual de crianças e adolescentes no Brasil: reflexões teóricas, relatos de pesquisas e intervençōes psicossociais. São Paulo: Casa do Psicólogo.

Morais, N. A., Cerqueira-Santos, E., Moura, A. S., Vaz, M. \& Koller, S. (2007). Exploração sexual comercial de crianças e adolescentes: um estudo com caminhoneiros brasileiros. Psicologia: Teoria e Pesquisa, 23 (3), 263272.

Ozella, S. (2002). Adolescência: uma perspectiva crítica. In M. L. Contini \& S. H. Koller (Org.), Adolescência e Psicologia: concepçôes, práticas e reflexōes críticas. Rio de Janeiro: Conselho Federal de Psicologia. 
Pereira, F.M.G. (2004). O corpo jovem e o medo do envelhecimento. In Alvin, R; Ferreira Júnior, E. \& Queiroz, T. (Orgs.), (Re) Construçôes da juventude: Cultura e Representações contemporâneas. João Pessoa: Editora Universitária PPGS/UFPB.

Polícia Rodoviária Federal - PRF (2010). Guia para a Localização dos Pontos vulneráveis à Exploração Sexual Infanto-juvenil ao longo das rodovias Federais Brasileiras/Mapeamento 2009-2010. Escritório Internacional do trabalho.

Resolução $n^{\circ}$ 196, de 10 de outubro de 1996 (Outubro, 1996). Recuperado de http://www.conselho.saude.gov.br/resoluçoes/1996/reso196.doc.

Sá, G. P. (1998). A construção do objeto de pesquisa em representaçôes sociais. Rio de Janeiro: Ed. UERJ.

Saffioti, H. I. B. (2000). Exploração Sexual de Crianças. In A. A. Azevedo \& V. N. de A. Guerra (Orgs.), Crianças vitimizadas: a sindrome do pequeno poder. (2a ed., pp. 49-95). São Paulo: Iglu.

Sarti, C. A. (2003). A familia como espelho: um estudo sobre a moral dos pobres. (2a ed.). São Paulo: Cortez.

Teixeira, L. C. (2003). Sentido subjetivo da exploração sexual para uma adolescente prostituída. In S. Ozella (Org.), Adolescências construidas. São Paulo: Cortez.

Vygotsky, L. S. (2007). A formação Social da mente. J. C. Neto, L. S. M. Barreto \& S. C. Afeche (Trad.). (7a ed.). São Paulo: Martins Fontes.

Williams, T. P., Binagwaho, A. \& Betancourt, T. S. (2012). Transactional sex as a form of child sexual exploitation and abuse in Rwanda. Child Abuse \& Neglect, 36, 354-361. 